\title{
LOGÍSTICA REVERSA DE EQUIPAMENTOS ELETROELETRÔNICOS: UMA ANÁLISE DO SISTEMA NO BRASIL
}

\author{
REVERSE LOGISTICS OF ELECTRO-ELECTRONIC EQUIPMENT: \\ AN ANALYSIS OF THE SYSTEM IN BRAZIL
}

\section{Isabel Conceição De Brida}

Graduada em Engenharia Química pela

Universidade do Sul de

Santa Catarina - UNISUL.

Especialista em Auditoria, Perícia e Gestão

Ambiental pelo Instituto de Pós-Graduação de

Goiás - IPOG. Mestranda em Energia e

Sustentabilidade pela

Universidade Federal de

Santa Catarina - UFSC. Email:

bel.brida@gmail.com

\section{RESUMO}

O Brasil é o maior gerador de resíduo eletrônico per capita entre os mercados emergentes e faltam estratégias para lidar com tal questão. O sistema de logística reversa de resíduos eletroeletrônicos deve ser estruturado e mantido pelos fabricantes, importadores, distribuidores e comerciantes. No entanto, falta desenvolver uma infraestrutura que possa assegurar a máxima eficiência de todo o processo. Desse modo, o objetivo da pesquisa é analisar a forma pela qual o sistema de logística reversa dos equipamentos eletroeletrônicos está sendo estruturado e implementado no país. Numa abordagem qualitativa, durante os meses de março e abril de 2015, foram realizadas entrevistas com os stakeholders envolvidos no processo, grande parte pertencente ao DF. Essas entrevistas e suas respectivas respostas foram fundamentais para entender a dinâmica de toda a cadeia de valor. Para analisá-las, empregou-se o referencial teórico da Agência Brasileira de Desenvolvimento Industrial (ABDI). Os resultados encontrados indicam que há pouca divulgação por parte da mídia, escolas, empresas fabricantes, universidades e outros sobre o tema e que a responsabilidade de retorno dos equipamentos eletroeletrônicos recai sobre o usuário. Concluiu-se que o maior desafio para concretizar o fluxo reverso está na mudança comportamental dos integrantes da cadeia, especialmente do setor empresarial.

Palavras-chave: Equipamento eletroeletrônico. Stakeholders. Logística reversa. Meio ambiente.

\footnotetext{
ABSTRACT

Brazil is the largest per capita generator of electronic waste among emerging markets and strategies are lacking to address this issue. The reverse electronics waste logistics system must be structured and maintained by manufacturers, importers, distributors and traders. However, infrastructure needs to be developed that can ensure maximum efficiency of the entire process. In this manner, the objective of the research is to analyze the way in which the reverse logistics system of electro-electronic equipment is being structured and implemented in the country. In a qualitative approach, during the months of March and April 2015, interviews were conducted with the stakeholders involved in the process, mostly from the Federal District (DF). These interviews and their responses were vital in understanding the dynamics of the entire value chain. To analyze them, the theoretical framework of the Brazilian Agency for Industrial Development (ABDI) was used. The results found show that there is little disclosure by the media, schools, manufacturing companies, universities and others on the subject and that the responsibility for the return of electronic equipment rests with the user. It was concluded that the biggest challenge to bring about the reverse flow is in the behavioral change of the chain members, especially the business sector.

Keywords: Electro-electronic equipment. Stakeholders. Reverse logistic. Environment.
} 


\section{INTRODUÇÃO}

A popularização de produtos tecnológicos criou um problema que tende a se agravar ainda mais nos próximos anos: a questão dos resíduos eletroeletrônicos.

Aproximadamente, no Brasil, 680 mil toneladas desses resíduos são jogadas fora por ano. As substâncias químicas presentes nos eletrônicos, ao penetrarem no solo, podem entrar em contato com lençóis freáticos e acabar contaminando plantas e animais por meio da água. Com isso, é possível que a ingestão dos alimentos intoxique os humanos. As consequências vão desde simples dor de cabeça e vômito até complicações mais sérias, como o comprometimento do sistema nervoso e surgimento de cânceres.

A Política Nacional dos Resíduos Sólidos (PNRS), aprovada em 2010, foi regulamentada pelo Decreto n. 7.404. Entre os diversos pontos tratados no decreto, alguns se destacam como:

a) a gestão dos resíduos sólidos deve buscar, nessa ordem, a não geração, redução, reutilização, reciclagem, tratamento de resíduos e disposição final ambientalmente adequada;

b) o sistema de logística reversa de resíduo eletroeletrônico deverá ser estruturado e mantido pelos fabricantes, importadores, distribuidores e comerciantes; e

c) obrigação dos consumidores em disponibilizar adequadamente seus resíduos sólidos para coleta e devolução, sempre que houver sistema de coleta seletiva municipal ou sistema de logística reversa.

Desse modo, tendo em vista que já se passaram cinco anos desde a regulamentação da norma, pode-se questionar: de que forma o sistema de logística reversa dos equipamentos eletroeletrônicos está sendo estruturado e implementado no Brasil?

Estabelecer um sistema de logística reversa traz a oportunidade de se pensar e criar condições para a promoção do desenvolvimento social via geração de empregos, negócios sustentáveis e capacitação de mão de obra.

A indústria da reciclagem não é parte considerada na PNRS como corresponsável pela gestão dos resíduos sólidos, mas é parte imprescindível para a efetividade dos objetivos da lei. Valorização e incentivo da utilização de matérias-primas recicladas, dentro da etapa de manufatura, são bases para o fortalecimento da empresa de reciclagem.

Além disso, o meio ambiente requer processos que persigam a máxima eficiência, tendo em vista o ideal de aterro zero. Por mais que se busque uma alta eficiência na recuperação e reciclagem de materiais, o processamento de resíduos eletroeletrônicos sempre gera uma quantidade de rejeito - material cujo reaproveitamento é inviável. Como ele é composto muitas vezes por elementos potencialmente perigosos, é necessário adotar medidas de minimização de seu impacto socioambiental. Ao contrário de outros tipos de resíduos, no caso dos eletroeletrônicos a valorização energética (incineração com subsequente transformação de calor em energia elétrica) não é recomendada (FRANCO, 2008). 
Uma vez que o equipamento entre no sistema de logística reversa, fará parte de uma cadeia de processos que irão culminar em sua reciclagem ou neutralização de seus componentes. As etapas da logística reversa são: descarte, coleta ou recebimento, triagem, reciclagem e disposição final. Cada uma dessas fases será desenvolvida em diferentes organizações, conectadas pelo sistema de logística reversa.

Assim, para o Sistema de Limpeza Urbana (SLU, 2015) do Distrito Federal, o termo reciclagem significa: "É o processo de transformação de um material, cuja primeira utilidade terminou, em outro produto. Além de preservar o meio ambiente, a partir do momento que minimiza a retirada de nova matéria-prima, também gera riquezas aos catadores de materiais recicláveis".

Mano, Pacheco e Bonelli (2010, p. 113) entendem que, "Na reciclagem, o que se aproveita é o material para ser transformado em uma nova peça ou para recuperar energia, fazendo retornar ao ciclo produtivo parte das matérias-primas ou da energia".

Entretanto, Franco (2008, p. 35) considera que "Reciclagem é o processo de transformação dos resíduos sólidos que envolvem a alteração de suas propriedades físicas, físico-químicas ou biológicas, com vistas à transformação em insumos ou novos produtos".

No entender de Leite (2003, p. 7), "Reciclagem é o canal reverso de revalorização, em que os materiais constituintes dos produtos descartados são extraídos industrialmente, transformando-se em matérias-primas secundárias ou recicladas, que serão reincorporadas à fabricação de novos produtos".

O exemplo mais ilustrativo é o da valorização dos metais em geral: são extraídos de diferentes tipos de produtos descartados ou de resíduos industriais, para se constituírem em matérias-primas secundárias a serem reintegradas ao ciclo produtivo (LEITE, 2003, p. 7).

Ao se comparar as citações acima, observou-se que as ideias convergem entre si, porém o conceito do Sistema de Limpeza Urbana (SLU), talvez por ser o mais atual, mostra certa preocupação com a questão ambiental e que se pode gerar uma fonte de renda às pessoas envolvidas no processo.

\title{
2 A LOGÍSTICA REVERSA
}

De acordo com a Agência Brasileira de Desenvolvimento Industrial (ABDI), a logística reversa é:

\begin{abstract}
Um instrumento de desenvolvimento econômico e social caracterizado por um conjunto de ações, procedimentos e meios destinados a viabilizar a coleta e a restituição dos resíduos sólidos ao setor empresarial, para reaproveitamento, em seu ciclo ou em outros ciclos produtivos, ou outra destinação final ambientalmente adequada (ABDI, 2012, p. 15).
\end{abstract}

É por meio desse sistema, por exemplo, que materiais recicláveis de um produto eletrônico em fim de vida útil descartado pelo consumidor poderão retornar ao setor produtivo na forma de 
matéria-prima.

Conforme Dias (2005, p. 205), "Logística reversa, também conhecida como logística inversa, reversível ou verde, é a área da logística que trata, genericamente, do fluxo físico de produtos, embalagens ou outros materiais, desde o ponto de consumo até o local de origem".

Já em Stock (1998, p. 20) encontra-se a definição: “Logística reversa: em uma perspectiva de logística de negócios, o termo refere-se ao papel da logística no retorno de produtos, redução na fonte, reciclagem, substituição e reuso de materiais, disposição de resíduos, reforma, reparação e remanufatura".

Entretanto, para Dornier et al., a definição de logística abrange áreas de atuação novas, incluindo o gerenciamento dos fluxos reversos:

Logística é a gestão de fluxos entre funções de negócio. A definição atual de logística engloba maior amplitude de fluxos do que no passado. Tradicionalmente, as empresas incluíam a simples entrada de matérias-primas ou o fluxo de saída de produtos acabados em sua definição de logística. Hoje, no entanto, essa definição expandiu-se e inclui todas as formas de movimentos de produtos e informações (2000, p. 39).

Além dos fluxos diretos considerados, a logística moderna engloba, entre outros, os fluxos de retorno de peças a serem reparadas, de embalagens e seus acessórios, de produtos vendidos devolvidos e de produtos usados ou consumidos a serem reciclados.

Bowersox e Closs (2001, p. 51) apresentam, por sua vez, a ideia de "apoio ao ciclo de vida" como um dos objetivos operacionais da logística moderna, referindo-se ao seu prolongamento além do fluxo direto dos materiais e à necessidade de considerar os fluxos reversos de produtos em geral.

No entender de Leite, a logística reversa é

[...] a área da logística empresarial que planeja, opera e controla o fluxo e as informações logísticas correspondentes, do retorno dos bens de pós-venda e de pós-consumo ao ciclo de negócios ou ao ciclo produtivo, por meio dos canais de distribuição reversos, agregando-lhes valor de diversas naturezas (2003, p. 16)..

Empresas modernas utilizam a logística reversa, diretamente ou por meio de terceirizações com empresas especializadas, como forma de ganho de competitividade no mercado. Para Leite (2003, p. 17), a logística reversa agrega valor econômico, ecológico, legal e de localização, ao planejar as redes reversas e as respectivas informações e ao operacionalizar o fluxo, desde a coleta dos bens de pós-consumo até a reintegração ao ciclo.

As diversas definições e citações de logística reversa revelam que o conceito ainda está em evolução, em face de novas possibilidades de negócio, relacionadas com o crescente interesse empresarial e por pesquisas na área, na última década. 


\subsection{O RESÍDUO ELETROELETRÔNICO}

Constituem bens de pós-consumo os produtos em fim de vida útil ou usados com possibilidade de reutilização e os resíduos industriais em geral (LEITE, 2003, p. 18). Para a ABDI (2012), equipamentos eletroeletrônicos são todos aqueles produtos cujo funcionamento depende do uso de corrente elétrica ou de campos eletromagnéticos. Podem ser divididos em quatro categorias amplas:

a) Linha Branca: refrigeradores e congeladores, fogões, lavadoras de roupa e louça, secadoras, condicionadores de ar;

b) Linha Marrom: monitores e televisores de tubo, plasma, LCD e LED, aparelhos de DVD e VHS, equipamentos de áudio, filmadoras;

c) Linha Azul: batedeiras, liquidificadores, ferros elétricos, furadeiras, secadores de cabelo, espremedores de frutas, aspiradores de pó, cafeteiras;

d) Linha Verde: computadores desktop e laptops, acessórios de informática, tablets e telefones celulares.

Ao final de sua vida útil, esses produtos passam a ser considerados resíduos de equipamentos eletroeletrônicos (REEE). São compostos por materiais diversos: plásticos, vidros, componentes eletrônicos, mais de vinte tipos de metais pesados e outros. Sua separação para processamento e eventual reciclagem têm uma complexidade, um custo e um impacto muito maiores que aqueles exemplos mais conhecidos de recolhimento e tratamento de resíduos, como são os casos das latas de alumínio e das garrafas de vidro, entre outros (ABDI, 2012, p. 17).

Algumas características próprias dos REEE justificam a exigência de processos específicos de gerenciamento. Alguns dos materiais encontrados neles são metais pesados, como alumínio, arsênio, cádmio, bário, cobre, chumbo, mercúrio e cromo, entre outros.

Para Franco (2008), todos esses elementos são potencialmente tóxicos e podem contaminar as pessoas que manipulam tais resíduos, não apenas aquelas envolvidas com a coleta, triagem, descaracterização e reciclagem, como também o consumidor que mantém e utiliza em casa equipamentos antigos.

Ainda, de acordo com Franco (2008), os REEE não devem em nenhuma hipótese ser depositados diretamente na natureza ou junto a rejeitos orgânicos. Mesmo em aterros sanitários, o mero contato dos metais pesados com a água incorre em imediata contaminação do chorume, multiplicando o impacto decorrente de qualquer eventual vazamento. Penetrando no solo, esse material pode contaminar lençóis subterrâneos ou acumular-se em seres vivos, com consequências negativas para o ambiente como um todo.

Soma-se a isso que um grande volume de REEE é exportado continuamente de países ricos para destinos como Nigéria, Índia, Paquistão, Uganda, China e outros. Nesses locais, os resíduos 
eletroeletrônicos acabam sendo processados de maneira totalmente inadequada, por pessoal não qualificado e em condições precárias. Frequentemente, os rejeitos são lançados diretamente na natureza, como no solo dos lixões a céu aberto, ou no ar, em forma de fumaça proveniente da queima descontrolada de materiais.

Portanto, como forma de combater o transporte dos resíduos eletrônicos de países desenvolvidos para países em desenvolvimento e alertar para os perigos de seus componentes tóxicos, houve uma iniciativa internacional em 1989, chamada Convenção da Basileia. Porém, mesmo assim, vários países ignoram o disposto e continuam a exportar tais resíduos para os continentes asiático e africano. Na Figura 1, pode-se observar a disposição inadequada de resíduos eletroeletrônicos:

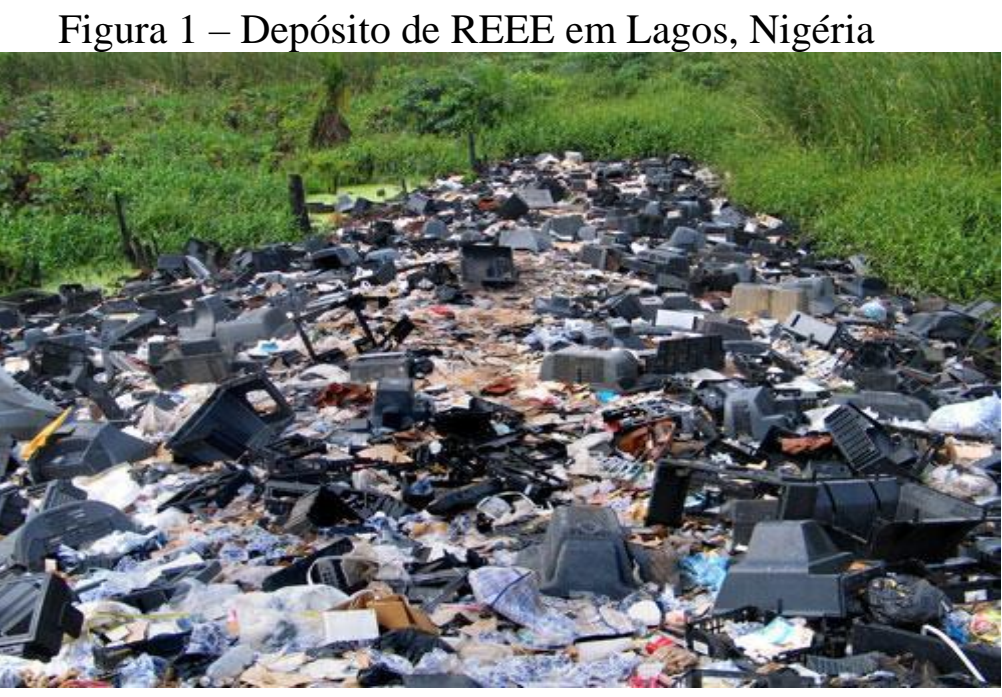

Fonte: BAN (2005).

\subsubsection{Situação no Brasil}

No Brasil, não havia legislação e regulamentação nacionais que oferecessem o respaldo jurídico necessário para o desenvolvimento de uma infraestrutura abrangente responsável pelo tratamento desse tipo de resíduo (ABDI, 2012, p. 19).

Essa situação pode ser atribuída a uma tardia industrialização, e os resíduos eletroeletrônicos não pareciam ser uma prioridade. Pode-se também responsabilizar a falta de interesse da opinião pública e da mídia em relação a questões ambientais cotidianas. Mais recentemente, esses fatores começaram a mudar no sentido de uma maior conscientização da sociedade, embora ainda haja um longo caminho a percorrer.

De acordo com a Lei 12.305/2010, que institui a Política Nacional de Resíduos Sólidos (PNRS), a responsabilidade compartilhada pelo ciclo de vida dos produtos a ser implementada de forma individualizada e encadeada abrange os fabricantes, importadores, distribuidores, comerciantes, consumidores e os titulares dos serviços públicos de limpeza urbana e de manejo de resíduos sólidos (PNRS, 2010, art. 30). 
Tal responsabilidade tem por objetivo promover o aproveitamento de resíduos sólidos, direcionando-os para a sua cadeia produtiva ou para outras cadeias produtivas, reduzir a geração de resíduos sólidos, o desperdício de materiais, a poluição e os danos ambientais e incentivar a utilização de insumos de menor agressividade ao meio ambiente e de maior sustentabilidade, entre outros (PNRS, 2010, art. 30).

Ainda, conforme estabelece a PNRS, são obrigados a estruturar e implementar sistemas de logística reversa, mediante retorno dos produtos após o uso pelo consumidor, de forma independente do serviço público de limpeza urbana e de manejo dos resíduos sólidos, os fabricantes, importadores, distribuidores e comerciantes de produtos eletroeletrônicos e seus componentes (PNRS, 2010, art. $33)$.

Em 2009, um estudo publicado pelo Programa das Nações Unidas para o Meio Ambiente (PNUMA) reportava sobre a situação dos resíduos eletroeletrônicos em onze países em desenvolvimento. Nesse contexto, o Brasil era o país que relativamente mais produzia REEE, com uma média acima de meio quilograma per capita ao ano. De acordo com a pesquisa, o tempo médio de uso de um celular está em torno de quatro anos, o que implica em praticamente 28 milhões de aparelhos sendo descartados anualmente pelos brasileiros (PNUMA, 2009).

Assim sendo, uma das consequências desse consumo desenfreado é o aumento no volume de resíduo sólido gerado. Sem um sistema estruturado que receba todo esse descarte, grande porção dele vai parar no mercado informal. Parte dos equipamentos é absorvida para o reuso, por vezes operada por agentes alheios à questão ambiental.

\subsubsection{Iniciativas de coleta e reuso de resíduos eletroeletrônicos}

À espera da legislação que atribuísse a devida responsabilidade sobre os REEE, surgiram algumas iniciativas espontâneas na área. Em especial, em relação a tecnologias de comunicação e informática, foram criados projetos da sociedade civil organizada, como a ONG CDI, coletivos informais, como a rede MetaReciclagem, programas governamentais, como os Centros de Recondicionamento de Computadores (CRCs - criados no Ministério do Planejamento e posteriormente transferidos ao Ministério das Comunicações), e experiências na universidade como o CEDIR (Centro de Descarte e Reuso de Resíduos de Informática), na USP (ABDI, 2012, p. 20).

A produção de conhecimento específico sobre REEE aumentou significativamente no Brasil. Representantes do país estiveram presentes na reunião da plataforma RELAC (Resíduos Eletrônicos na América Latina e Caribe) no Panamá, ao fim de 2009. O Porto Digital, de Recife, organizou duas edições do SIREE (Seminário Internacional de Resíduos Eletroeletrônicos), reunindo representantes das diferentes partes interessadas na questão. Projetos como o CE-WASTE analisam possíveis arranjos locais ou regionais para a questão. E organizações, como o IDEC (Instituto de Defesa do 
Revista Tecnologia e Ambiente, v. 25, 2019, Criciúma, Santa Catarina/SC ISSN Eletrônico 2358-9426 e ISSN Impresso 1413-8131

Consumidor), também têm debatido os resíduos eletroeletrônicos (ABDI, 2012, p. 21).

Além disso, a criação da Agenda Ambiental na Administração Pública (A3P) foi uma iniciativa governamental preconizada pelo Ministério do Meio Ambiente (MMA). Essa agenda é um programa que visa sensibilizar os gestores públicos para as questões socioambientais, estimulandoos a adotarem princípios e critérios de gestão ambiental nas atividades administrativas. Na cartilha desse programa, constam os resíduos eletroeletrônicos, enfatizando a necessidade de dar uma destinação adequada a eles (A3P, 2012).

No que tange à legislação local, governos estaduais e municipais também têm se interessado sobre a questão dos resíduos eletroeletrônicos. Em 2010, já existiam legislações específicas, por exemplo no estado de São Paulo e no município de Curitiba. Legislativos municipais e estaduais de diversas localidades estão no momento estudando, debatendo ou tramitando projetos específicos, naturalmente acelerados com a aprovação da PNRS em 2010.

Segundo o jornal Correio Brasiliense, no Distrito Federal existe a captação do lixo eletrônico, realizada por duas empresas particulares e outra não governamental, na região do entorno, que trabalham em parceria com o Serviço de Limpeza Urbana (SLU). Todo material coletado passa por uma triagem, responsável por separar os itens que ainda estão em condições de uso dos que já não funcionam mais. Aqueles que são recuperados têm como destino a inclusão digital (CORREIO BRASILIENSE, 2013).

E, ainda, o decreto de setembro de 2011, que determina a Política Distrital de Resíduos Sólidos, também trata da reciclagem de materiais tecnológicos. No entanto, falta a regulamentação de uma política reversa.

\subsubsection{Ciclo de vida dos produtos eletroeletrônico}

O ciclo de vida de um produto descreve a história completa dele ao longo de sua vida útil, passando pelas fases de concepção, definição, produção, operação e obsolescência. Segundo a Agência Brasileira de Desenvolvimento Industrial (ABDI), “[...] a logística reversa visa 'fechar’ esse ciclo ao promover a reciclagem do produto obsoleto retornando ao mercado matérias-primas recicladas e dispondo os rejeitos de forma ambientalmente adequada" (ABDI, 2012, p. 26).

É importante destacar que a logística reversa só começa quando um consumidor de fato descarta o seu equipamento eletroeletrônico, esteja esse em condições de uso ou não, tenha o equipamento passado pela fase de reuso ou não. Na Figura 2, o ciclo de vida dos produtos eletroeletrônicos é apresentado: 
Figura 2 - Ciclo de vida dos produtos eletroeletrônicos

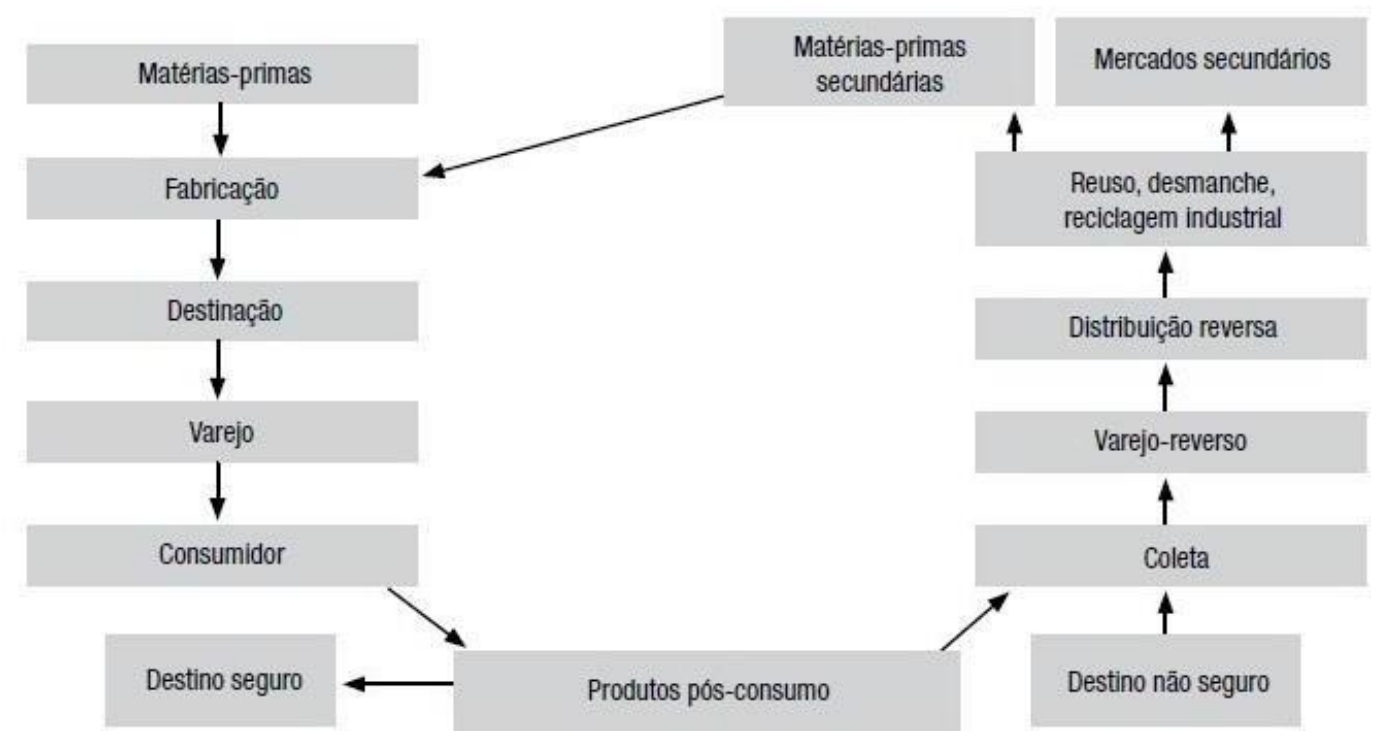

Fonte: Muller (2005)

Para Leite (2003, p. 20), o aumento da velocidade de descarte dos produtos de utilidade após seu primeiro uso, motivado pelo nítido aumento da descartabilidade dos produtos em geral, não encontrando canais de distribuição reversos de pós-consumo devidamente estruturados, provoca desequilíbrio entre as quantidades descartadas e as reaproveitadas, gerando um enorme crescimento de produtos de pós-consumo.

\subsubsection{Cadeia produtiva na logística reversa}

A manufatura e a importação são responsáveis por inserir os resíduos eletroeletrônicos no mercado nacional. Segundo a Associação Brasileira da Indústria Elétrica e Eletrônica (ABINEE, 2012), a indústria eletroeletrônica faturou R $\$ 138$ bilhões em 2011, um crescimento de $11 \%$ em relação ao ano anterior.

As etapas de criação, concepção, fabricação e montagem são realizadas entre diversas empresas. Em alguns casos, como nos equipamentos de informação e comunicação, é frequente que duas marcas diferentes encomendem a produção para uma mesma fabricante terceirizada. Por conta das características específicas da manufatura de equipamentos eletrônicos e do cenário internacional de matérias-primas, a importação tem um papel fundamental na manufatura. Muitos componentes e subcomponentes são importados - em especial de países do leste asiático - para posterior montagem dentro do Brasil (ABDI, 2012, p. 27).

Além disso, de acordo com a ABINEE (2012), a China é a maior origem das importações de equipamentos eletrônicos para o país, contando com 35\% de participação em 2011. Do total de R \$ 39,5 bilhões em importações de eletroeletrônicos, os equipamentos de telecomunicações, informática 
e utilidades domésticas somam $\mathrm{R} \$ 12,6$ bilhões. Representam mais de 4\% das importações totais do Brasil. Os importadores mais representativos são as distribuidoras atacadistas e revendedores para o varejo, sendo que eles possuem responsabilidade legal em relação aos produtos importados.

Por conta de seu relacionamento direto com o consumidor, o comércio representa um excelente potencial para ações de logística reversa. No entanto, para a Agência Brasileira de Desenvolvimento Industrial (ABDI, 2012):

\begin{abstract}
No que tange ao gerenciamento de REEE, o comércio tem desafios específicos a enfrentar. Uma delas é em relação à estrutura física: os pequenos e médios comerciantes já dispõem de pouco espaço livre em suas instalações. Dependendo da demanda, a coleta de resíduos eletroeletrônicos pode exigir uma disponibilidade que eles não têm como oferecer. Soma-se a isso, o fato de o reuso não ser atraente para o varejo, entre outros motivos, por levantar questões complexas de garantia, assistência e risco socioambiental. Por outro lado, o comércio já entende como sua responsabilidade cotidiana o diálogo com o consumidor, para o qual se torna referência natural em tudo que se refere aos produtos vendidos ou anunciados. Essa característica pode transformar o varejo em um forte aliado no que se refere à divulgação de informações a respeito do descarte correto de REEE (ABDI, 2012, p. 33).
\end{abstract}

Os eletroeletrônicos cada vez mais fazem parte da vida cotidiana do brasileiro. Com o aumento do poder de compra das classes $\mathrm{C}$ e $\mathrm{D}$, milhões de famílias passaram a adquirir produtos que anteriormente não tinham condições de comprar. A decisão sobre a compra costuma passar por etapas distintas: reconhecimento da necessidade, busca de informação, avaliação das alternativas do produto, decisão de compra e comportamento pós-compra, entre outras. Após o consumo, os produtos podem ser descartados por diferentes motivos (ABDI, 2012, p. 31).

Para Mano, Pacheco e Bonelli (2010, p. 114), a coleta seletiva é caracterizada pela separação dos materiais da fonte pela população, com posterior coleta e envio às usinas de triagem, cooperativas, sucateiros, beneficiadores ou recicladores. A implementação da coleta seletiva constitui a principal ação para o desenvolvimento da reciclagem e da reutilização.

De acordo com a Agência Brasileira de Desenvolvimento Industrial (ABDI 2012), a coleta de REEE consiste no recebimento, armazenamento temporário e encaminhamento desse tipo de material. Porém, a coleta precisa seguir uma série de regulamentações. Por exemplo, o consumidor precisa assinar um termo de doação dos equipamentos dos quais está se desfazendo. Além disso, os estabelecimentos que se dispuserem a receber materiais precisam obter licenciamento ambiental específico, considerando que a lei trata o resíduo eletroeletrônico como material perigoso.

Outro canal com grande potencial para realizar a coleta de REEE são as oficinas de assistência técnica: estabelecimentos que realizam o conserto ou a manutenção de aparelhos eletrônicos em geral. Segundo a Associação Brasileira de Serviço em Eletroeletrônicos (ABRASA) (2012), existem mais de 10 mil oficinas em todo o país. Sua expansão costuma acompanhar o crescimento do mercado em áreas como telefones celulares, informática e outras. 
Além disso, as cooperativas de catadores costumam fazer a coleta, triagem e em alguns casos até a desmontagem de REEE. É comum que utilizem caminhões para coleta programada nos bairros que atendem, não trabalhando mais com a figura do carroceiro. Muitos não se adaptam à rotina de obrigações das cooperativas e preferem trabalhar individualmente. Desse modo, apesar do maior risco, podem chegar a ter um faturamento maior (ABDI, 2012, p. 35).

Entre os problemas enfrentados pelas cooperativas está a existência das "cooperativas de fachada", que exploram mão de obra barata, mas não adotam uma postura verdadeiramente cooperativa. Como resultado, todo o setor se enfraquece e perde credibilidade.

De acordo com a revista Veja, muitos materiais utilizados originalmente na fabricação de equipamentos eletroeletrônicos vêm de diversas localidades. Por exemplo, grande parte do cobre utilizado como condutor elétrico é extraído de minas chilenas. Já o silício, utilizado como semicondutor em circuitos eletrônicos, é extraído de diferentes regiões em todo o planeta. No caso do tântalo, elemento utilizado na fabricação de celulares, era encontrado em abundância na natureza. No entanto, especialistas preveem que em vinte anos as únicas jazidas desse metal serão os lixões e os aterros sanitários, para onde irão os telefones rejeitados (VEJA, 2014).

Por mais que se busque uma alta eficiência na recuperação e reciclagem de materiais, o processamento de resíduos eletroeletrônicos sempre gera uma quantidade de rejeito - material cujo reaproveitamento é inviável. Como ele é composto muitas vezes por elementos potencialmente perigosos, é necessário adotar medidas de minimização de seu impacto socioambiental. Ao contrário de outros tipos de resíduos, no caso dos eletroeletrônicos a valorização energética (incineração com subsequente transformação de calor em energia elétrica) não é recomendada. A opção que resta é a distribuição ordenada dos rejeitos em aterros, observando as normas operacionais específicas (FRANCO, 2008).

\subsubsection{Metodologia}

O presente estudo consiste em uma investigação exploratória qualitativa, utilizando entrevista estruturada como instrumento principal de coleta de dados.

Numa abordagem qualitativa, durante os meses de março e abril de 2015 , foram realizadas as entrevistas com os stakeholders envolvidos no processo de logística reversa dos equipamentos eletroeletrônicos, grande parte pertencente ao DF e identificados:

a) no Poder Público: Ministério do Meio Ambiente e SLU;

b) no Setor Privado: Zero Impacto, Microsoft do Brasil, CRV, High Tech, loja de informática, supermercado Carrefour Bairro; e

c) Terceiro Setor: ONG Programando o Futuro. E, ainda, os consumidores, os quais também 
Revista Tecnologia e Ambiente, v. 25, 2019, Criciúma, Santa Catarina/SC ISSN Eletrônico 2358-9426 e ISSN Impresso 1413-8131

participaram.

Além disso, foram utilizados outros instrumentos de pesquisa, como: diário de campo, gravador, fotos, questionário do Google Docs, consulta à bibliografia geral e específica e dados estatísticos, entre outros.

Buscou-se entrevistar pessoas com larga experiência e que estão relacionadas com o processo de logística reversa de resíduos eletroeletrônicos. Foram entrevistados no SLU três gestores, na Secretaria de Recursos Hídricos e Ambiente Urbano, do Ministério do Meio Ambiente, uma analista ambiental, na Central de Reciclagem do Varjão (CRV), uma funcionária e, na assistência técnica autorizada de Brasília, o proprietário. E, ainda, três Pontos de Entrega Voluntária (PEVs) foram pesquisados. Aos consumidores, foi aplicado o questionário do Google Docs, por meio de perguntas fechadas, nas páginas de alguns órgãos ambientais da rede social Facebook. Optou-se por realizar entrevistas via correio eletrônico nas demais instituições, devido à distância ou à indisponibilidade dessas.

Essas entrevistas foram fundamentais para entender a dinâmica de toda a cadeia de valor. Contudo, trata-se de um campo amplo e muito complexo. Primeiramente, quando se trata de questões econômicas, as empresas não estão dispostas a revelar dados com honestidade e, em segundo, foram encontradas dificuldades relacionadas à heterogeneidade dos atores sociais envolvidos e a disponibilidade, em ambos os casos, para a realização de entrevistas.

\subsection{ANÁliSE DO SISTEMA DE LOGÍSTICA REVERSA DOS EQUIPAMENTOS ELETROELETRÔNICOS}

Apresentam-se os resultados das pesquisas de campo e via correio eletrônico, realizadas nos meses de março e abril de 2015, com os stakeholders da cadeia envolvidos no processo, grande parte pertencente ao DF.

O objetivo da pesquisa é analisar a forma pelo qual o sistema de logística reversa dos equipamentos eletroeletrônicos está sendo estruturado e implementado no país.

\subsubsection{O consumidor}

O questionário foi respondido por 62 pessoas e ficou disponível na rede social Facebook pelo período de um mês. Quando se perguntou onde eram descartados os eletrônicos em desuso, 62,9\% responderam que guardavam em casa, 25,8\% nos pontos de coleta e 11,3\% no lixo doméstico, conforme apresenta a figura 3 a seguir:

Figura 3 - Locais para o descarte dos produtos eletrônicos 


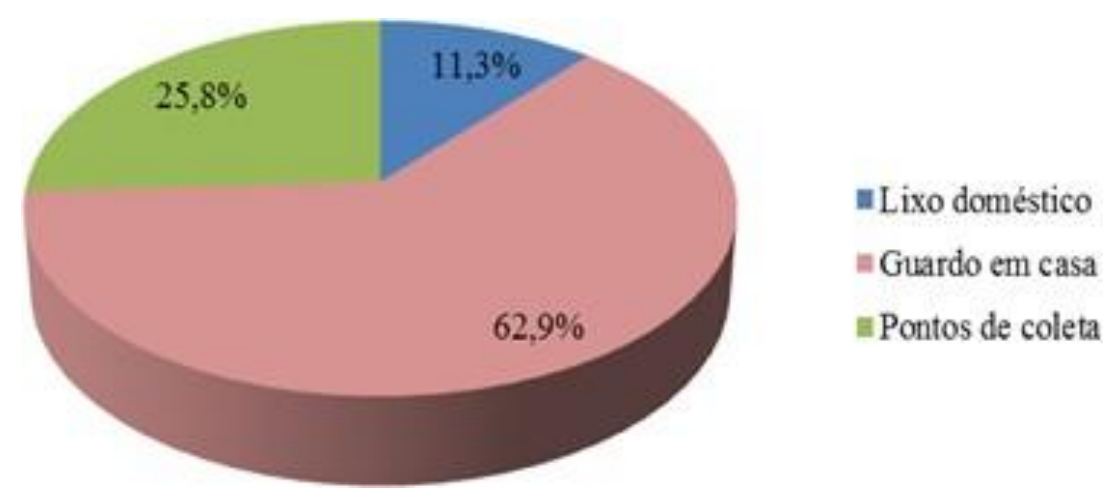

Fonte: Elaborado pela autora (2015).

Principalmente por falta de uma estrutura adequada de coleta e de informação a esse respeito, o consumidor brasileiro não tem o hábito de dar destinação adequada a seus resíduos, sendo que 11,3\% dos entrevistados ainda descartam os equipamentos eletrônicos no lixo doméstico. Isso pode ser confirmado pela Agência Brasileira de Desenvolvimento Industrial (ABDI, 2012), quando menciona que existem frequentes casos de pessoas e empresas que depositam esse tipo de material junto ao resíduo comum. A persistência de uma cultura do reuso faz com que parte do material eletroeletrônico seja guardada, doada ou vendida.

Além disso, a grande maioria disse conhecer a lei da Política Nacional dos Resíduos Sólidos, mas $29,5 \%$ não têm o conhecimento da norma.

Quando se trata em mudar hábitos de uma sociedade, o papel da escola torna-se importantíssimo. Aparentemente, a educação ambiental encontra-se inserida nos currículos de escolas do mundo inteiro. No entanto, grande parte dos professores se resume a uma abordagem superficial dos temas relacionados ao meio ambiente.

Ainda, de acordo com o questionário, quando se perguntou onde obtiveram informações para o descarte correto dos equipamentos, 1,6\% responderam panfletos, 3,2\% website da empresa fabricante, $9,7 \%$ jornais, $27,4 \%$ não buscam por informações e $58,1 \%$ internet, conforme ilustrado na Figura 4:

Figura 4 - Meios utilizados para a obtenção de informações 


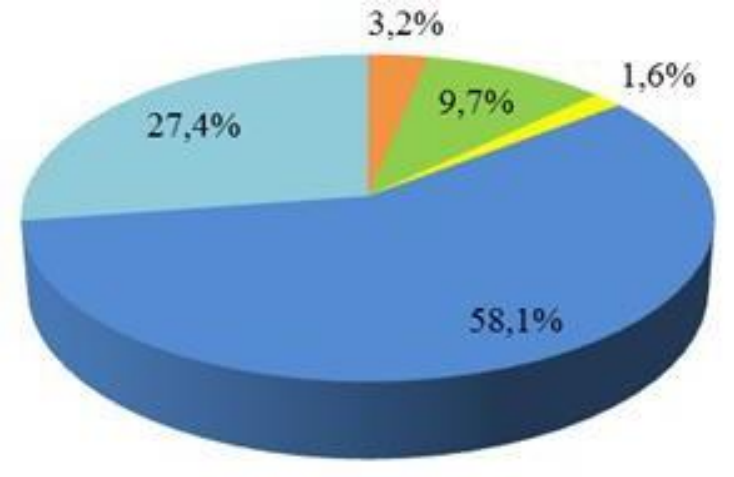

Fonte: Elaborado pela autora (2015).
$=$ Website da empresa fabricante

\#omais

Panfletos

winternet

wão busco por informações

Analisando o gráfico, apenas 3,2\% das pessoas disseram obter informações no website da empresa fabricante. Isso demonstra falhas nos programas de comunicação das empresas fabricantes, sendo essas responsáveis por estruturar e implementar sistemas de logística reversa dos equipamentos, após o uso pelo consumidor. É preocupante saber que $27,4 \%$ não buscam por informações. Por outro lado, 93,5\% estariam dispostos a se deslocar até um ponto de coleta para o descarte correto e $85,2 \%$ têm conhecimento sobre as consequências prejudiciais ao meio ambiente do descarte incorreto dos resíduos eletrônicos.

Quando se questionou se era um fator decisivo para a próxima compra saber que a empresa fabricante se preocupa com o descarte correto, $58,1 \%$ responderam que sim. E, ainda, $100 \%$ levariam seus aparelhos usados, na hora em que fossem comprar um novo, caso as empresas oferecessem descontos.

Todo consumo causa impacto na economia, nas relações sociais e na natureza. Ao ter consciência desses impactos na hora de escolher o que comprar, de quem comprar e definir a maneira de como descartar o que não serve mais, o consumidor pode maximizar os impactos positivos e minimizar os negativos, tornando-se um comprador consciente de fato.

Desse modo, o consumidor pode adotar a filosofia dos "3 Rs", visto que é necessário Reduzir o volume do produto a ser descartado, Reutilizar as embalagens/produtos e, por último, Reciclar, aproveitando o material para ser transformado em uma nova peça.

\subsubsection{Pontos de Entrega Voluntária (PEVs)}

Por conta de sua posição privilegiada e de seu relacionamento direto com o consumidor, o comércio representa um excelente potencial para ações de logística reversa. Nos últimos anos, com a conscientização do consumidor e a busca por práticas sustentáveis pelo mundo empresarial, têm surgido diversas iniciativas espontâneas de coleta de materiais eletrônicos. Alguns bancos, supermercados, universidades, shoppings, assistências técnicas, ONGs, operadoras de telefonia 
Revista Tecnologia e Ambiente, v. 25, 2019, Criciúma, Santa Catarina/SC ISSN Eletrônico 2358-9426 e ISSN Impresso 1413-8131

móvel, entre outros, ajudam a receber os equipamentos descartados pelo consumidor.

Foram pesquisadas duas lojas de informática e o supermercado Carrefour Bairro, todos localizados na Asa Norte em Brasília. Quando se questionou o que levou o estabelecimento a fazer a coleta dos resíduos eletroeletrônicos, todas as instituições mencionaram que se preocupam com a questão ambiental. As lojas de informática não tinham espaço suficiente para armazenar os equipamentos, apenas o Carrefour respondeu ter um local apropriado. Nenhum dos três estabelecimentos apresentava um termo de doação dos equipamentos, para que o consumidor assinasse e o licenciamento ambiental específico, para poder recolher os materiais. O supermercado Carrefour Bairro disse que existe um contrato de prestação de serviços, fornecido pela empresa recicladora, a qual busca diariamente os resíduos (somente pilhas e baterias).

Tais resultados divergem daqueles já citados pela (ABDI, 2012), já que, segundo a agência, o consumidor precisa assinar um termo de doação dos equipamentos dos quais está se desfazendo e os estabelecimentos que se dispuserem a receber os materiais precisam obter licenciamento ambiental específico.

E, ainda, quando questionados para onde iria todo o material coletado, a primeira loja disse que para a ONG Inversa da Asa Norte e também para a Universidade de Brasília (UNB). Já a segunda loja respondeu que quem faz a coleta é uma transportadora. Essa pesa certa quantidade de resíduo e paga um valor (definido por ela) à loja de informática, para então revender às empresas de reciclagem. E, por último, a empresa recicladora Capital Recicláveis faz a coleta dos materiais no supermercado Carrefour, diariamente.

\subsubsection{Assistência técnica}

As oficinas de assistência técnica já atuam informalmente como pontos de recebimento de equipamentos eletroeletrônicos em fim de vida útil. Muitos consumidores abandonam equipamentos defeituosos cujo conserto tenha elevado custo, portanto seja tecnicamente inviável.

A High Tech é uma empresa autorizada na manutenção em garantia de aparelhos celulares e acessórios da Microsoft, situada em Brasília. De acordo com o proprietário, a assistência técnica faz parceria com a Microsoft a respeito da logística reversa dos equipamentos eletrônicos, sendo que esses são recolhidos pela empresa recicladora GM\&CLOG, de São José dos Campos/SP.

Segundo o website da GM\&CLOG, a companhia se especializou em logística reversa devido ao alto volume de produtos colocados no mercado que necessitam voltar ao fabricante ou ter sua destinação final ambientalmente correta. A instituição atende às leis ambientais aplicáveis no transporte, manuseio, armazenamento, tratamento e destinação final dos resíduos. E, ainda, no transporte possui uma equipe bem treinada, utiliza embalagens adequadas e homologadas conforme 
Revista Tecnologia e Ambiente, v. 25, 2019, Criciúma, Santa Catarina/SC ISSN Eletrônico 2358-9426 e ISSN Impresso 1413-8131

Resolução da ANTT 420 e os motoristas possuem habilitação especial para cargas perigosas.

\subsubsection{ONG Programando o Futuro}

Coordenado pela ONG Programando o Futuro, o projeto Estação de Metarreciclagem tem como objetivo fornecer um espaço para reciclagem de resíduo eletrônico e de treinamento de jovens e adultos em oficinas de informática. O trabalho da Estação de Metarreciclagem foi iniciado em 2003, em uma parceria entre a Organização Não Governamental e a Fundação Banco do Brasil. Além de Valparaíso de Goiás (GO), as estações estão em operação nas cidades de Samambaia (DF), Teresina (PI), Contagem (MG) e São Paulo (SP).

De acordo com o coordenador da ONG, são produzidos por mês na sede em Valparaíso de Goiás, 25 mil toneladas de produtos recicláveis como ferro, alumínio, cobre, borracha, vidro, plástico e placas de computadores. Todo esse material vira matéria-prima para a indústria depois de passar pelo processo de recomposição nas empresas que atuam na área da reciclagem no Brasil. Apenas as placas de computadores são exportadas para empresas recicladoras canadenses

Além disso, a estação proporciona cursos e oficinas gratuitos para aquelas pessoas que se interessarem pelo mundo da informática: manutenção de computadores, informática básica, eletrônica e robótica. Também são oferecidas vagas de estágio remunerado para jovens de baixa renda, que irão atuar no processo de desmontagem e recuperação de computadores. Nesse caso, os equipamentos que apresentarem condições de uso serão recondicionados e doados para escolas, entidades sem fins lucrativos e bibliotecas públicas.

Os equipamentos eletrônicos descartados por empresas privadas, órgãos públicos e residências particulares são coletados pela estação. Para o coordenador, a maior responsabilidade do projeto é dar a esses resíduos um destino final ambientalmente correto.

\subsection{SERVIÇO DE LIMPEZA URBANA (SLU)}

O Serviço de Limpeza Urbana (SLU) foi uma das primeiras instituições ambientalistas do Distrito Federal. Atualmente, está subordinado à Secretaria de Desenvolvimento Urbano e Meio Ambiente do DF. Segundo o SLU, lixo eletrônico é “[...] todo resíduo produzido pelo descarte de equipamentos eletrônicos, como: computadores e periféricos (teclado, monitor, mouse, webcam), telefones, celulares, pilhas, baterias, televisores, câmeras fotográficas, impressoras e outros" (SLU, 2015).

No Distrito Federal, ainda não há um projeto de coleta seletiva voltado para esse tipo de material. Existem 21 núcleos funcionais, pertencentes ao SLU, chamados de Pontos de Entrega Voluntária (PEVs), que recebem os resíduos. Os pontos aceitam eletroeletrônicos como telefones 
(fixos e celulares), TVs, aparelhos de som, batedeiras e torradeiras, entre outros. Produtos da linha branca, como geladeiras e fogões, não são coletados. Dos pontos, os resíduos eletrônicos são encaminhados para as cooperativas ou às empresas que realizam o desmonte, reutilização e reciclagem desses.

De acordo com os gestores do SLU, atualmente o Distrito Federal conta com 32 instituições de catadores, com um total de três mil trabalhadores. A população do DF produz em média 800 quilos de resíduos eletrônicos por mês, e os produtos mais descartados são monitores e torres de computador. Segundo eles, o SLU não tem a obrigação de recolher o resíduo eletrônico. Por lei, são os fabricantes, importadores, distribuidores e comerciantes que deverão estruturar e implementar sistemas de logística reversa.

\subsection{CENTRO DE RECICLAGEM DO VARJÃO (CRV)}

As cooperativas de catadores costumam fazer a coleta, triagem e em alguns casos até o préprocessamento (desmontagem) de resíduo eletroeletrônico.

O Centro de Reciclagem do Varjão é uma associação de catadores, localizada no município de Varjão/DF, onde apenas mulheres trabalham no local, separando o lixo orgânico do reciclável. O material orgânico é recolhido pelo SLU, e o restante, como papelão, caixa de leite e plástico, é vendido para a empresa Capital Recicláveis.

De acordo com uma das catadoras, a associação recebe o lixo de coleta seletiva do SLU e também equipamentos eletroeletrônicos da população do entorno de Varjão, como rádio, TV, microondas, geladeira e CPU, entre outros. E, ainda, existe uma parceria do CRV com o GEA e a Caixa Econômica Federal. Segundo a funcionária da associação, a CRV possui um caminhão, doado pela FUNASA, que faz a coleta do material eletrônico na APCEF de Brasília e na Caixa Econômica Federal de Ceilândia.

No processo de triagem do resíduo eletrônico, as catadoras retiram apenas as partes plásticas. O restante do material é comprado por transportadoras, que revendem para empresas recicladoras de São Paulo. Na Figura 5, tem-se a sala de depósito para os resíduos do CRV:

Figura 5 - Sala de depósito para os resíduos do CR 


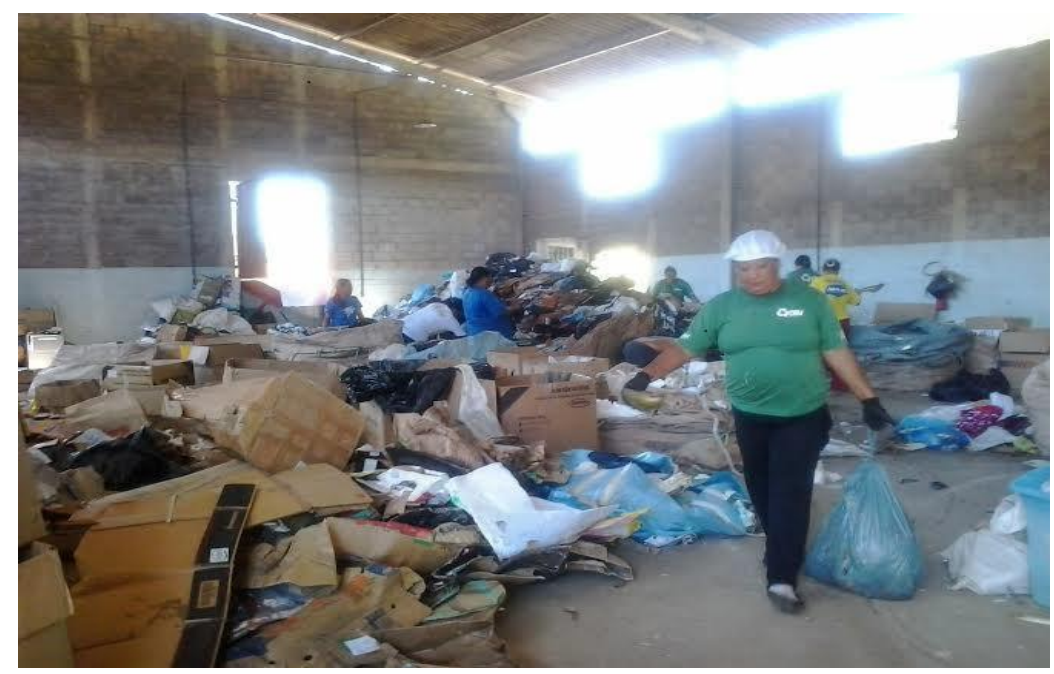

Fonte: Acervo da autora (2015).

\subsection{EMPRESA DE RECICLAGEM}

Através da reciclagem, os resíduos eletroeletrônicos dão origem à matéria-prima não virgem que pode ser devidamente reinserida no processo produtivo, reduzindo a demanda por extração de nova matéria-prima. Os insumos gerados pela reciclagem de REEE não serão necessariamente utilizados para a mesma finalidade. Alguns materiais irão, por exemplo, para a indústria cerâmica ou de pigmento (ABDI, 2012, p. 36).

Enquanto não sai a regulamentação da logística reversa, o resíduo eletrônico vai recebendo tratamento adequado apenas quando empresas conscientes ambientalmente promovem ações nesse sentido. A Zero Impacto E-Reciclagem atua no gerenciamento de resíduos eletroeletrônicos, com exceção dos itens da linha branca (geladeira, freezer, ar condicionado e outros) desde 2010 e conta com 11 pontos públicos de coleta à disposição do brasiliense.

Ao se questionar qual a tecnologia de manufatura reversa para o reaproveitamento dos resíduos, o gestor da empresa respondeu ser: desmonte, separação por tipo de material e encaminhamento para as indústrias de transformação e fabricação. Além disso, segundo ele, a empresa não possui tecnologia para fazer o total reaproveitamento, portanto foi feita parceria com uma empresa italiana, líder em reciclagem, o que possibilitou o contato com o que há de mais avançado em termos de tecnologia para o tratamento de REEE.

Para Bohr (2007), isso de fato acontece, pois, em termos de separação e tratamento de insumos nobres de resíduos eletrônicos, o Brasil tem baixa eficiência quando comparado com tecnologias existentes em outros países. Parte considerável dos resíduos eletroeletrônicos gerados no país precisa, desse modo, ser exportada para o devido tratamento.

Um levantamento realizado no sistema Aliceweb apontou que, em 2011, um volume superior a 20.000 toneladas de resíduos potencialmente originados de equipamentos eletroeletrônicos foi 
Revista Tecnologia e Ambiente, v. 25, 2019, Criciúma, Santa Catarina/SC ISSN Eletrônico 2358-9426 e ISSN Impresso 1413-8131

exportado a partir do Brasil, conforme demonstração da tabela a seguir:

\begin{tabular}{|c|c|c|c|c|c|c|}
\hline $\begin{array}{l}\text { Tipo de } \\
\text { Resíduo }\end{array}$ & 2006 & 2007 & 2008 & 2009 & 2010 & 2011 \\
\hline $\begin{array}{c}\text { Polímeros e } \\
\text { outros } \\
\text { plásticos }\end{array}$ & 13.826 & 12.409 & 7.984 & 3.946 & 5.473 & 5.772 \\
\hline Ferro & 7.317 & 19.571 & 30.705 & 18.842 & 9.815 & 15.774 \\
\hline $\begin{array}{c}\text { Acumulador } \\
\text { Elétrico }\end{array}$ & - & - & - & - & 6 & 32 \\
\hline Vidro & - & 145 & 4 & 14 & 7 & - \\
\hline Total & 21.143 & 32.126 & 38.693 & 22.802 & 15.300 & 21.579 \\
\hline
\end{tabular}

Fonte: ABDI (2012).

Além disso, nem todo insumo é revertido em novos produtos, sendo que passivos ambientais (como tonner, cartuchos, disquetes, fitas K7) não possuem tecnologia suficiente para seu total reaproveitamento. Então, tornam-se rejeitos, tendo como destino mais comum a incineração para geração de energia.

De acordo com o gestor da Zero Impacto, são processadas por mês cinco toneladas de material e os equipamentos coletados que ainda podem servir são destinados à inclusão digital, por meio do Comitê da Democratização da Informática (CDI), com a garantia de tornar inacessível quaisquer dados remanescentes.

Mesmo frente a um crescente esforço institucional no estímulo à reciclagem, existem poucos mecanismos legais para proporcionar isenções fiscais nessa atividade. Uma reivindicação do setor é que a reciclagem passe a ter uma carga tributária mais condizente com a sua vital importância na sociedade.

\subsection{EMPRESA FABRICANTE}

A manufatura dos equipamentos eletroeletrônicos é caracterizada por forte integração. As etapas de criação, concepção, fabricação e montagem são realizadas entre diversas indústrias: de plástico, borracha, mecânica, química, eletrônica, minero-metalurgia e software, entre outras.

Em anos recentes, tem havido bastante questionamento sobre escolhas que já começam no nível do design de equipamentos eletroeletrônicos. Uma das características criticadas é a ausência de padrões nos acessórios, particularmente nos fones de ouvido, cartões de memória e carregadores de 
Revista Tecnologia e Ambiente, v. 25, 2019, Criciúma, Santa Catarina/SC ISSN Eletrônico 2358-9426 e ISSN Impresso 1413-8131

energia de telefones celulares e produtos similares.

Também é criticada a restrição deliberada ao reparo dos aparelhos - reforçada pela ausência de peças de reposição ou em alguns casos pela total impossibilidade de substituição de peças. Para ABDI (2012), essa tendência faz parte da chamada obsolescência programada, juntamente com a adoção de medidas que reduzem a vida útil dos produtos e do uso da publicidade para incentivar sua frequente substituição.

Algumas empresas têm respondido a tais críticas incentivando o ecodesign, que parte de uma visão sistêmica e integrada para desenvolver produtos, sistemas ou serviços com reduzidos impactos ambientais. A Microsoft, por exemplo, desenvolveu um protótipo de telefone celular que reutiliza plástico de garrafas de água em sua fabricação. Entretanto, o produto não tem data de lançamento por conta da ausência de uma cadeia produtiva estruturada para o fornecimento de material.

O programa Alô Recicle da Microsoft do Brasil, em parceria com o grupo Pão de Açúcar, existe desde 2010 para a reciclagem de celulares, acessórios e baterias. Os pontos para descarte dos equipamentos estão instalados em locais de fácil acesso, no interior das lojas, próximos ao Serviço de Atendimento ao Cliente (SAC). Todos os materiais coletados são recolhidos pela companhia e encaminhados para um centro de triagem, na cidade de São José dos Campos/SP. De lá, seguem para o exterior - as baterias são encaminhadas para um parceiro na cidade do México, e o restante do material vai para Chicago, nos Estados Unidos, para ser totalmente reciclado.

Dessa forma, as matérias-primas coletadas se transformam em novos produtos, como brinquedos, eletrônicos, produtos odontológicos, joias e até pavimento asfáltico. Também podem ser utilizadas como fonte de energia no próprio processo de reciclagem.

Por fim, representantes da manufatura expressam a expectativa de que a logística reversa deve ser compartilhada de forma isonômica entre os atores do setor e com outros elos da cadeia. Do mesmo modo, eles esperam contrapartidas do poder público para compartilhar custos do sistema, já que esse, muitas vezes, não é implementado, pelo fato de as empresas considerarem sua operacionalização complexa e cara.

\subsection{MISTÉRIO DO MEIO AMBIENTE (MMA)}

Os sistemas de logística reversa serão implementados e operacionalizados por meio dos seguintes instrumentos: acordos setoriais, regulamentos ou termos de compromisso.

De acordo com o Decreto n. 7.404/2010, os acordos setoriais são atos de natureza contratual, firmados entre o Poder Público e os fabricantes, importadores, distribuidores ou comerciantes, visando à implementação da responsabilidade compartilhada pelo ciclo de vida do produto. Ainda, de acordo com o decreto, a logística reversa poderá ser implantada diretamente por regulamento, 
veiculado por decreto editado pelo poder executivo ou também por meio dos termos de compromisso. O poder público poderá celebrar termos de compromisso com os fabricantes, importadores, distribuidores ou comerciantes, nas hipóteses em que não houver, em uma mesma área de abrangência, acordo setorial ou regulamento específico, ou para a fixação de compromissos e metas mais exigentes que o previsto em acordo setorial ou regulamento.

Conforme a analista ambiental do Ministério do Meio Ambiente, ainda não há um acordo setorial definido. A cadeia (empresas, importadores, distribuidores e comerciantes) não entra em acordo entre si e ainda quer que o governo assuma com todas as despesas. Segundo ela, o que se tem são quatro propostas de acordos setoriais feitas entre as associações (ABINEE, ELETROS, ABRAS e ABRADISTI) e o setor empresarial.

Além disso, ainda não há incentivos fiscais para promover o mercado da reciclagem, como pela venda de produtos com conteúdo reciclável ou design ecológico. Por outro lado, “[...] nas etapas de coleta, armazenamento temporário e transporte, o resíduo eletrônico não será considerado como sendo perigoso", explica a analista.

De acordo com a ABDI (2012), para que isso ocorra é necessário que o poder público legisle sobre o tema. Uma das condições impostas ao sistema de logística reversa e que pode facilitar as mudanças na legislação para atendimento da condição de resíduo não perigoso é que não se promova qualquer modificação físico-química do REEE ao longo do manuseio e transporte até uma recicladora. Essa deverá obter licenciamento ambiental para manuseio e processamento de tal resíduo. Dessa forma, minimiza-se o risco à exposição de material perigoso de contaminação durante a logística (ABDI, 2012).

Segundo a analista, por enquanto não estão sendo cobradas taxas de impostos (transporte interestadual) sobre a mercadoria eletrônica circulante. O IBAMA é que irá cuidar dessa etapa.

É necessário que os consumidores mudem seus hábitos na hora de comprar e descartar eletrônicos. Para a analista, hoje existe um apelo muito grande para que os usuários comprem sempre novos produtos. Por isso, a especialista defende que os usuários prolonguem ao máximo a vida útil de seus produtos. Na hora de descartá-los, os eletrônicos devem ser doados (caso ainda funcionem) ou disponibilizados em postos de coleta, para que tenham a destinação adequada.

\section{CONCLUSÃO}

O consumidor é o ponto de partida do fluxo reverso, no entanto, por falta de informações, acaba dificultando o processo e esse não funciona de forma adequada. A responsabilidade de retorno dos equipamentos eletroeletrônicos recai sobre o usuário e esse, desinformado, não cumprirá com sua real função na cadeia de reciclagem, visto que a grande maioria guarda os produtos em casa. 
Pode-se dizer que há pouca divulgação por parte da mídia, escolas, governos, universidades e das empresas fabricantes sobre o tema. Também se constatou a falta de interesse dos usuários pela busca de informações corretas, na hora do descarte dos equipamentos. Ainda, os resultados sugerem que não adianta apenas possuir canais reversos, pois eles não funcionarão corretamente se as informações sobre a forma de retorno dos produtos não forem plenamente divulgadas.

Soma-se a isso que as instituições estão perdendo a oportunidade de fidelizar o cliente em relação à marca, visto que $100 \%$ dos consumidores levariam seus aparelhos usados, na hora em que fossem comprar um novo, caso as empresas oferecessem descontos.

Além disso, durante as entrevistas nos Pontos de Entrega Voluntária, pôde-se observar a falta de espaço para o armazenamento dos equipamentos. E, ainda, nenhum dos estabelecimentos pesquisados tinha licenciamento ambiental específico, considerando que a lei trata o resíduo eletroeletrônico como material perigoso. Todo o processo ocorre de maneira informal e falta uma logística adequada para recolher e levar os produtos até o destino final.

Nas assistências técnicas também falta espaço para o armazenamento dos produtos. Com o avanço de tecnologias e equipamentos sem peças de substituição, um volume de resíduos que precisam, urgentemente, de reparos e destino final adequado vem aumentando.

No Brasil, o setor de reciclagem sofre de instabilidade no fornecimento de materiais, ocasionado pela alta informalidade da coleta e da logística. Em decorrência da escala ainda relativamente reduzida, faltam também ao setor condições de investir em tecnologia de ponta. Por esse motivo, parte considerável dos resíduos gerados no país precisa ser exportada para o devido tratamento.

A falta de incentivo do poder público, em especial na esfera municipal, tem contribuído com a precarização do trabalho das cooperativas. Elas poderiam contar com maior capacitação, o que possibilitaria agregar valor nas atividades que desenvolvem.

Apesar de ser um grande problema e da possibilidade de gerar grandes danos ao meio ambiente, ainda não existe uma lei específica para cuidar do descarte dos resíduos eletrônicos. De acordo com o Ministério do Meio Ambiente, ainda não há um acordo setorial definido. O que existe são quatro propostas de acordos setoriais feitas entre as associações (ABINEE, ELETROS, ABRAS e ABRADISTI) e o setor empresarial.

Argumenta-se, com base nos resultados desta pesquisa, que o maior desafio para concretizar o fluxo reverso de equipamentos eletroeletrônicos está na mudança comportamental dos integrantes da cadeia, especialmente do setor empresarial.

A pesquisa revelou um descompasso entre a intenção comportamental e o comportamento dos consumidores, potencializado pelo desconhecimento da lei e pela falta de informações a respeito do 
Revista Tecnologia e Ambiente, v. 25, 2019, Criciúma, Santa Catarina/SC ISSN Eletrônico 2358-9426 e ISSN Impresso 1413-8131

assunto.

Trata-se de um campo amplo e muito complexo, pois, quando se trata de questões econômicas, as empresas não estão dispostas a revelar dados com honestidade e, também, foram encontradas dificuldades relacionadas à heterogeneidade dos atores sociais envolvidos. A Microsoft do Brasil foi a única empresa que demorou a preencher o questionário via correio eletrônico e, de tanta insistência e ligações efetuadas para a sede da companhia em Manaus, acabou respondendo, entretanto, de forma restrita.

Algumas limitações devem ser sanadas em pesquisas futuras, como fazer levantamentos com mais atores da cadeia envolvida. E, por se tratar de uma pesquisa exploratória, os resultados não podem ser generalizados para o todo da indústria pesquisada, ainda que as empresas estudadas sejam as mais importantes do setor.

Um elemento a se considerar para futuras pesquisas é a integração da comunicação com incentivos monetários. Assim, uma comunicação que informe como o consumidor pode encaminhar seus resíduos pós-consumo e que valorize sua participação como corresponsável na mitigação de danos socioambientais, associado a algum incentivo econômico, potencializaria a devolução de equipamentos eletroeletrônicos.

Por fim, a implementação da logística reversa precisa superar vários desafios, como o desenvolvimento de uma infraestrutura que possa assegurar o recolhimento dos resíduos pósconsumo e a identificação de alternativas para garantir o seu reaproveitamento ou destino seguro.

\section{Referências}

A3P. Agenda Ambiental na Administração Pública. Ministério do Meio Ambiente, 2012. Disponível em: <http://www.ministeriodomeioambiente.gov.br/responsabilidade-socioambien tal/a3p/item/8852>. Acesso em: 5 maio 2015.

ABDI - Agência Brasileira de Desenvolvimento Industrial. Logística Reversa de Equipamentos Eletroeletrônicos: análise de viabilidade técnica e econômica. Distrito Federal, 2012. Disponível em: 〈http://www.abdi.com.br/Estudo/Logistica\%20reversa\% 20de\%20residuos_.pdf >. Acesso em: 15 mar. 2015.

ABINEE - Associação Brasileira da Indústria Elétrica e Eletrônica. A indústria elétrica e eletrônica impulsionando a economia verde e a sustentabilidade, 2012.

ABRASA. Pós-vendas e sustentabilidade ambiental, 2012.

BAN - Basel Action Network. Depósito de lixo eletrônico em Lagos. Nigéria, 2005. Disponível em: <http://www.ban.org/photogallery/nigeria_lagos/pages/image4969.html>. Acesso em: 3 maio 2015. BOHR, Philipp. The economics of electronics recycling: new approaches to extended producer responsibility, 2007.

BOWERSOX, Donald; CLOSS, David. Logística empresarial. São Paulo: Atlas, 2001.

DIAS, João Carlos Quaresma. Logística global e macrologística. Lisboa: Edições Sálabo, 2005.

DORNIER, Philippe Pierre. Logística e operações globais. São Paulo: Atlas, 2000.

FRANCO, Rosana Gonçalves Ferreira. Protocolo de Referência para Gestão de Resíduos de Equipamentos Elétricos e Eletrônicos Domésticos para o Município de Belo Horizonte. UFMG, 2008. 
GIGLIO, Ernesto Michelangelo. Comportamento do consumidor. São Paulo: Pioneira Thompson Learning, 2003.

GOVERNO FEDERAL. Lei n⿳ 12.305. Brasília, 2010.

GOVERNO FEDERAL. Decreto no 7.404. Brasília, 2010.

GM\&CLOG. Soluções em logística reversa e reciclagem. São Paulo, 2015. Disponível em: <http://www.gmclog.com.br/site/index.php/empresa1>. Acesso em: 6 maio 2015.

KOTLER, Philip; KELlER, Kevin Lane. Administração de marketing. São Paulo: Pearson Prentice Hall, 2006.

LEITE, Paulo Roberto. Logística reversa: meio ambiente e competitividade. São Paulo: Pearson Prentice Hall, 2003.

MACEDO, Michele. DF já conta com 13 pontos de entrega para descarte de lixo eletrônico. Correio brasiliense, Brasília, 2013. Disponível em: <http://www.correio braziliense.com.br/app/noticia/cidades/2013/10/11/interna_cidadesdf,392775/df-ja-conta-com-13pontos-de-entrega-para-descarte-de-lixo-eletronico.shtml>. Acesso em: 10 mar. 2015.

MANO, Eloisa; PACHECO, Élen Beatriz; BONELLI, Cláudia Maria. Meio Ambiente, poluição e reciclagem. São Paulo: Edgar Blucher, 2010.

MUELLER, Carla Fernanda. LR: meio ambiente e produtividade. Grupo de estudos logísticos da Universidade Federal de Santa Catarina, 2005.

PNUMA. Programa das Nações Unidas para o Meio Ambiente. Distrito Federal, 2009.

SLU. Serviço de Limpeza Urbana. Distrito Federal, 2015. Disponível em: <http://www. slu.df.gov.br/gestao-de-residuos/coleta-seletiva.html>. Acesso em: 2 abr. 2015.

STOCK, James. Reverse logistics programs: council of logistics management. Illinois, 1998.

TAHAN, Lilian; LANNES, Paulo. Os podres do nosso lixo. Revista Veja. Brasília, 2014. Disponível em: <http://vejabrasil.abril.com.br/brasilia/materia/os-podres-do-nosso-lixo-310>. Acesso em: 22 abr. 2015. 